\title{
Annual Fluxes of Heavy Metal Elements in Atmospheric Dry and Wet Depositions in the Pearl River Delta Economic Region, Guangdong Province
}

\author{
Lu Lu' ${ }^{1}$ Cen Kuang² \\ ${ }^{1}$ Beijing Institute of Geology, Beijing, China \\ ${ }^{2}$ School of Earth Sciences and Mineral Resources, China University of Geosciences (Beijing), Beijing, China \\ Email: 176224964@qq.com
}

How to cite this paper: Lu, L., \& Kuang, C. (2021). Annual Fluxes of Heavy Metal Elements in Atmospheric Dry and Wet Depositions in the Pearl River Delta Economic Region, Guangdong Province. Journal of Geoscience and Environment Protection, 9, 8-14.

https://doi.org/10.4236/gep.2021.95002

Received: March 26, 2021

Accepted: May 17, 2021

Published: May 20, 2021

\begin{abstract}
There are 158 sampling points to be set up in the Pearl River delta economic region. The collecting period is mostly one year, namely, from July 2007 to July 2008. The eight heavy metal elements of $\mathrm{Cr}, \mathrm{Ni}, \mathrm{Cu}, \mathrm{Pb}, \mathrm{Zn}, \mathrm{As}, \mathrm{Hg}$, and $\mathrm{Cd}$ in 474 dry and wet deposition samples were tested in terms of the standard procedures. Their average annual fluxes have no obvious difference between dry deposition and wet deposition. So these elements might be at an equilibrium or quasi-equilibrium state between dry deposition and wet deposition.
\end{abstract}

\section{Keywords}

Atmospheric Dry and Wet Deposition, Heavy Metal Element, Flux, Pearl River Delta Economic Region

\section{Introduction}

Heavy metal elements are main pollutions in the atmosphere into which they are mainly discharged by human activities (Al-Khashman, 2009). They are characterized by multiple sources (Das et al., 2010; Budhavant et al., 2011) and long-lasting suspending in the atmosphere (Gong Xiangyi et al., 2006), and especially they might be transformed into organic chemicals more toxic than themselves under some conditions. These pollutions elements are harmful to our health on one hand directly by entering our bodies through hands, mouths, noses, and skins 
and on the other hand indirectly by entering our food chains through a biogeochemical circle beginning with atmospheric dry and wet deposition (Cheng \& You, 2010). Therefore, heavy metal elements from atmospheric dry and wet deposition have become important indexes to monitor and assist the degree of atmospheric environmental pollution home and abroad (Han Yong-ming et al., 2006; Singh \& Mondal, 2008).

Our study region is the Pearl River delta economic region, Guangdong Province, which has been one of the high speed economic development regions in China. The people's life level there has significantly been promoted by the high speed economic development in recent more than 30 years, but such a development had brought about considerably serious environmental problems, especially the organic pollution of polycyclic aromatic hydrocarbons $(\mathrm{PAH})$ and the inorganic pollution of heavy metal elements. We are to focus on heavy metal elements from atmospheric dry and wet deposition in this region. In this paper, we reported the 2007-2008 monitoring results of these heavy metal elements, studied their space-time distributed characteristics using a multiple unit statistical method, and analyzed their comprehensive pollution level.

\section{Sampling and Testing}

We set up 128 sampling points throughout the study region. They were evenly assigned roughly in terms of landscape and administrative areas, but their density was doubled in the four serious atmospheric pollution areas of Guangzhou, Foshan, Dongguan, and Shenzhen. There are 474 samples of dry deposition and wet deposition to be collected. The collecting canisters should be placed at open and flat places which are far from chimneys, roads, pollution sources and so on. They should firmly be fixed to prevent them from moving by wind. Their mouths should be covered with nylon yarn nets to prevent others different from dry and wet depositions from entering them. Finally, a certain amount of distilled water should be maintained in these canisters to prevent dry deposition from scattering and disappearing during a long time of no raining. Collecting of dry and wet depositions in canisters as samples is carried out according to practical cases (Lu Lu et al., 2012).

The treat and test of samples were carried out in the Hefei Test Center of Mineral Sources, The Ministry of Land and Sources and the Central Lab of Institute of Geophysical and Geochemical Exploration, Chinese Academy of Geological Science, respectively. There are the eight elements of $\mathrm{Cr}, \mathrm{Ni}, \mathrm{Cu}, \mathrm{Pb}, \mathrm{Zn}$, As, $\mathrm{Hg}$, and $\mathrm{Cd}$ to be tested for all samples. For liquid samples (namely, liquid parts of samples) which did not need to extract previously, their $\mathrm{Cu}, \mathrm{Pb}, \mathrm{Zn}, \mathrm{Cd}$, $\mathrm{Cr}$, and $\mathrm{Ni}$ are tested directly using the ICP-MS method, while their As and $\mathrm{Hg}$ are tested using the AFS method.

\section{Data Analyses}

The data analyses of the test results were completed by Excel and SPSS. 


\subsection{Contents of Heavy Metal Elements}

In order to obtain the most typical contents of heavy metal elements in atmospheric dry and wet deposition, a sample in which the content of some element is more than its average plus three times of the standard deviation must be excluded before the data analyses. Moreover, a sample must be excluded even if it has only an element whose content exceeds the above standard.

A part of the statistical results for eight heavy metal elements in the tested samples and is listed in Table 1, including the corresponding data in some other sources for comparison. It can be seen that whatever samples are of dry deposition or of wet deposition, their average contents of the heavy metal elements are much more than those in soil in the same areas, in the crust, and in the Yangtze River water system. Moreover, both the average ratios of the contents of the eight elements in dry deposition to the corresponding contents in wet deposition samples and the averages of such ratios are arranged in the same order from high to low: $\mathrm{Cr}>\mathrm{Ni}>\mathrm{Cu}>\mathrm{Pb}>\mathrm{As}>\mathrm{Hg}>\mathrm{Cd}>\mathrm{Zn}$, although the two kinds of ratio have some systematic difference. Considering that the collecting period of most samples is one year, this arrangement order shows that these heavy metal elements be at an equilibrium or quasi-equilibrium state between dry deposition and wet deposition. So these ratios and their averages can be seen as the individual average distribution coefficients of these elements in the two phases. They mean that individual elements are assigned to the dry deposition and the wet

Table 1. Contents of heavy metal elements in atmospheric dry and wet deposition samples.

\begin{tabular}{|c|c|c|c|c|c|c|c|c|c|}
\hline \multicolumn{2}{|c|}{ Elements } & As & $\mathrm{Hg}$ & $\mathrm{Cd}$ & $\mathrm{Cr}$ & $\mathrm{Cu}$ & $\mathrm{Pb}$ & $\mathrm{Zn}$ & $\mathrm{Ni}$ \\
\hline \multicolumn{2}{|c|}{ Sample amount } & 149 & 153 & 128 & 129 & 115 & 133 & 122 & 133 \\
\hline \multirow{2}{*}{ Dry sample } & unit & $(\mu \mathrm{g} / \mathrm{g})$ & (ng/g) & (ng/g) & $(\mu \mathrm{g} / \mathrm{g})$ & $(\mu \mathrm{g} / \mathrm{g})$ & $(\mu \mathrm{g} / \mathrm{g})$ & $(\mu \mathrm{g} / \mathrm{g})$ & $(\mu \mathrm{g} / \mathrm{g})$ \\
\hline & average & 22.8 & 408.4 & 0.279 & 209.4 & 206.5 & 358.1 & 652.2 & 71.8 \\
\hline \multicolumn{2}{|c|}{$\begin{array}{l}\text { Average of the crust, } \\
\text { tong } 1990\end{array}$} & 2.2 & 89 & 0.200 & 110 & 63 & 12 & 94 & 89 \\
\hline \multicolumn{2}{|c|}{$\begin{array}{l}\text { Soil in Parcel River delta } \\
\text { (Zhu Lixin et al., 2002) }\end{array}$} & 13 & 87 & 0.350 & 69 & 28 & 36 & 95 & 28 \\
\hline \multirow{2}{*}{ Wet sample } & unit & $(\mu \mathrm{g} / \mathrm{L})$ & (ng/L) & $(\mathrm{ng} / \mathrm{L})$ & $(\mu \mathrm{g} / \mathrm{L})$ & $(\mu \mathrm{g} / \mathrm{L})$ & $(\mu \mathrm{g} / \mathrm{L})$ & $(\mu \mathrm{g} / \mathrm{L})$ & $(\mu \mathrm{g} / \mathrm{L})$ \\
\hline & average & 2.5 & 50.3 & 0.048 & 0.6 & 5.8 & 12.8 & 155.9 & 1.5 \\
\hline \multicolumn{2}{|c|}{$\begin{array}{l}\text { Yangtze River water system } \\
\text { (Zhang Licheng et al., 2006) }\end{array}$} & 0.88 & 23 & 0.02 & 0.9 & 1.26 & 0.71 & 4.18 & 0.61 \\
\hline \multirow{2}{*}{$\begin{array}{l}\text { Dry sample/wet } \\
\text { sample }\end{array}$} & unit & $(\mathrm{L} / \mathrm{g})$ & $(\mathrm{L} / \mathrm{g})$ & $(\mathrm{L} / \mathrm{g})$ & $(\mathrm{L} / \mathrm{g})$ & $(\mathrm{L} / \mathrm{g})$ & $(\mathrm{L} / \mathrm{g})$ & $(\mathrm{L} / \mathrm{g})$ & $(\mathrm{L} / \mathrm{g})$ \\
\hline & average & 20.3 & 16.7 & 8.8 & 586.0 & 141.4 & 60.2 & 6.8 & 240.0 \\
\hline $\begin{array}{l}\text { Average of dry } \\
\text { sample/average }\end{array}$ & unit & (L/g) & $(\mathrm{L} / \mathrm{g})$ & $(\mathrm{L} / \mathrm{g})$ & $(\mathrm{L} / \mathrm{g})$ & (L/g) & $(\mathrm{L} / \mathrm{g})$ & $(\mathrm{L} / \mathrm{g})$ & $(\mathrm{L} / \mathrm{g})$ \\
\hline of wet sample & ratio & 9.3 & 8.1 & 5.8 & 360.1 & 35.7 & 27.9 & 4.2 & 47.9 \\
\hline
\end{tabular}


deposition in different proportions. In other words, although from the existing information we do not definitely know the dissolutions of individual elements in the atmosphere, from their ratios between the two phases we can know not only their individual relative dissolutions, namely, a dissolution order inverse to the above arrangement order, but also their individual proportional relations in the two phases. These relations would depend on the chemical property of these heavy metal elements and at the same time show their characteristics of supergene behavior.

\subsection{Annual Fluxes of Dry Deposition and Wet Deposition}

As mentioned above, the collecting periods of samples are different, although most is one year. In order to correct errors due to such a difference, the collecting periods are standardized in terms of 365 days. Then the annual flux of dry and wet deposition for every sampling point is calculated by the following formulas:

$$
\begin{gathered}
F_{d}=D / a * C \\
C=365 / t
\end{gathered}
$$

where $F_{d}$ (unit: $\mathrm{g} / \mathrm{m}^{2}$ or $\mathrm{L} / \mathrm{m}^{2}$ ) is the annual flux of dry (or wet) deposition, $D$ (unit: $\mathrm{g}$ or $\mathrm{L}$ ) is the measured value of dry (or wet) deposition, $a$ (unit: $\mathrm{m}^{2}$ ) is the area of the collecting canister mouth, $C$ is the year coefficient, and $t$ is the day amount of actually collecting deposition in an year.

Given the mouth area of $436.74 \mathrm{~cm}^{2}$, it was obtained by calculation that the annual flux of the dry deposition is in a range of $12.13 \mathrm{~g} / \mathrm{m}^{2}-377.03 \mathrm{~g} / \mathrm{m}^{2}$, averaging $81.49 \mathrm{~g} / \mathrm{m}^{2}$, with a variation coefficient of 1.22 , while the annual flux of the wet deposition is in a range of $70.44 \mathrm{~L} / \mathrm{m}^{2}-1727.46 \mathrm{~L} / \mathrm{m}^{2}$, averaging 1218.40 $\mathrm{L} / \mathrm{m}^{2}$, with a variation coefficient of 4.01 . The contours of the annual fluxes of dry deposition (namely, atmospheric dust or air-fall) and wet deposition (namely, atmospheric precipitation) in the study region are shown in Figure 1 and

\section{Figure 2.}

It can be seen from Figure 1 that a crowd of high value points of the annual flux of dry deposition occur in the west part of Huizhou City where there are two obviously abnormal areas. One is located between Gongzhuang Town and Mapi Town in the north part of Boluo County; another is located near Zhenlong Twon of Huiyang District.

Other high value points are scattered in the east part of Huizhou, within Shenzhen urban area, in the juncture between Guangzhou City and Dongguan City, from Danzao Town to Nanhai Town in the central part of Foshan City, in Dawang Town on the west margin of Zhaoqing City, and from Baoan to Fuyong in the west part of Shenzhen City.

Middle value points are seen in the south and north parts of Jiangmen and Zhongshan Cities, and throughout the Zhuhai City and throughout Guangzhou, Foshan, and Zhaoqing Cities, where there also are some low value points. 


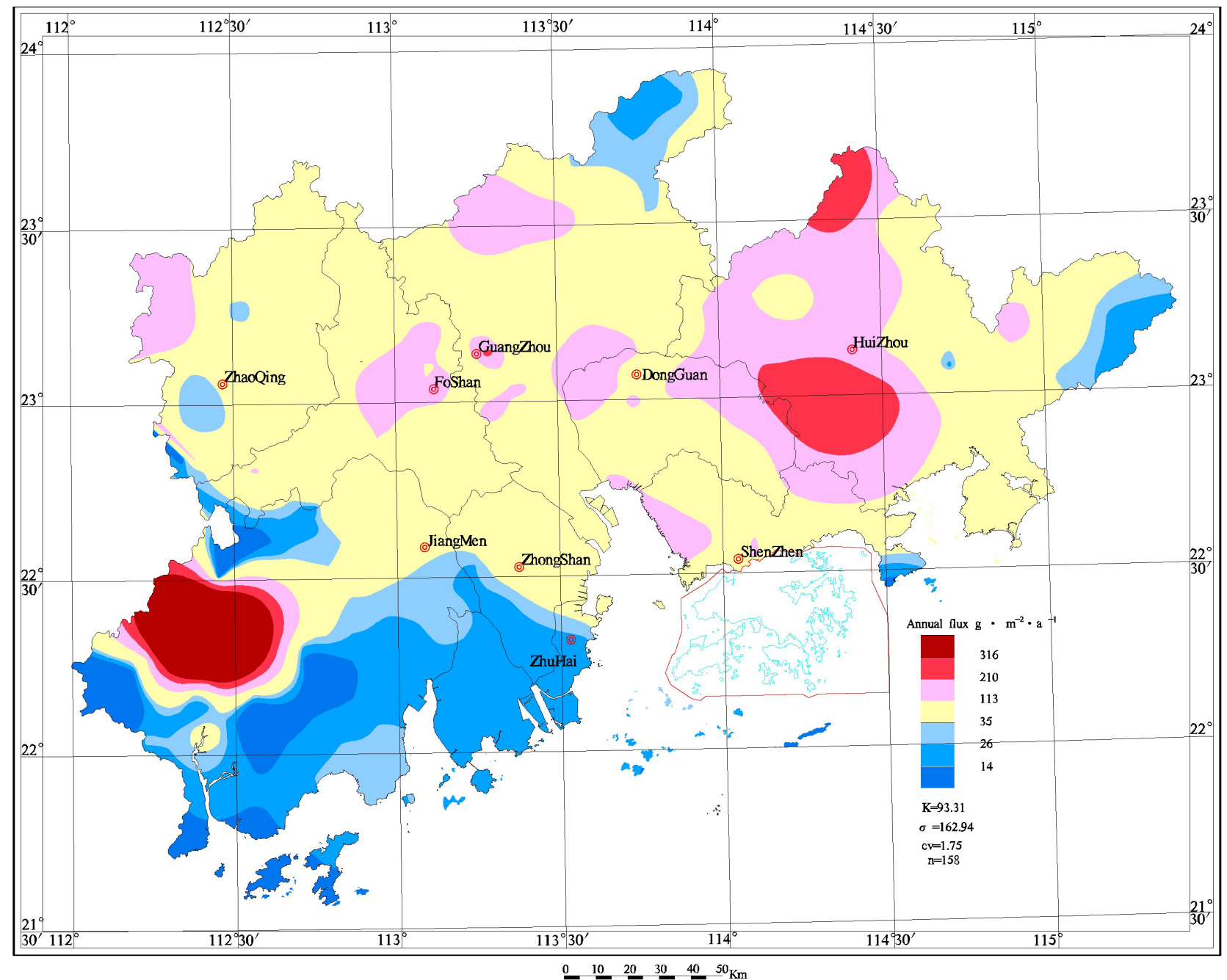

Figure 1. Distribution of annual flux of dry deposition (Namely, atmospheric dust or air fall) in the Parcel River delta.

In fact, these high and middle value points are highly discharging places of industrial waste material. For example, according to the in-situ investigation, there are many cement mills in these two places. They might be the main cause to lead the high flux of dry deposition.

However, there is a high value point near Guangtang Town, Enping, in the west part of Jiangmen City. By checking the original data, the high value there is due to the dry deposition collected in sampling point No. 306. This sample is a few ten times heavier than samples around other sampling points. Moreover, its element association is obviously different from that of nearby samples. This is not normal. If this sampling point is excluded, the area near Guangtang Town like the nearby areas will be of a low value. It seems to us that there are two possibilities to cause this abnormal case: one is due to a high discharging source or another is due to a problem with sampling. What actually caused it will remain to further investigate.

On the other hand, it can be seen from Figure 2 that low value points of the annual flux of wet deposition are scattered in the most of Foshan and Zhaoqing 


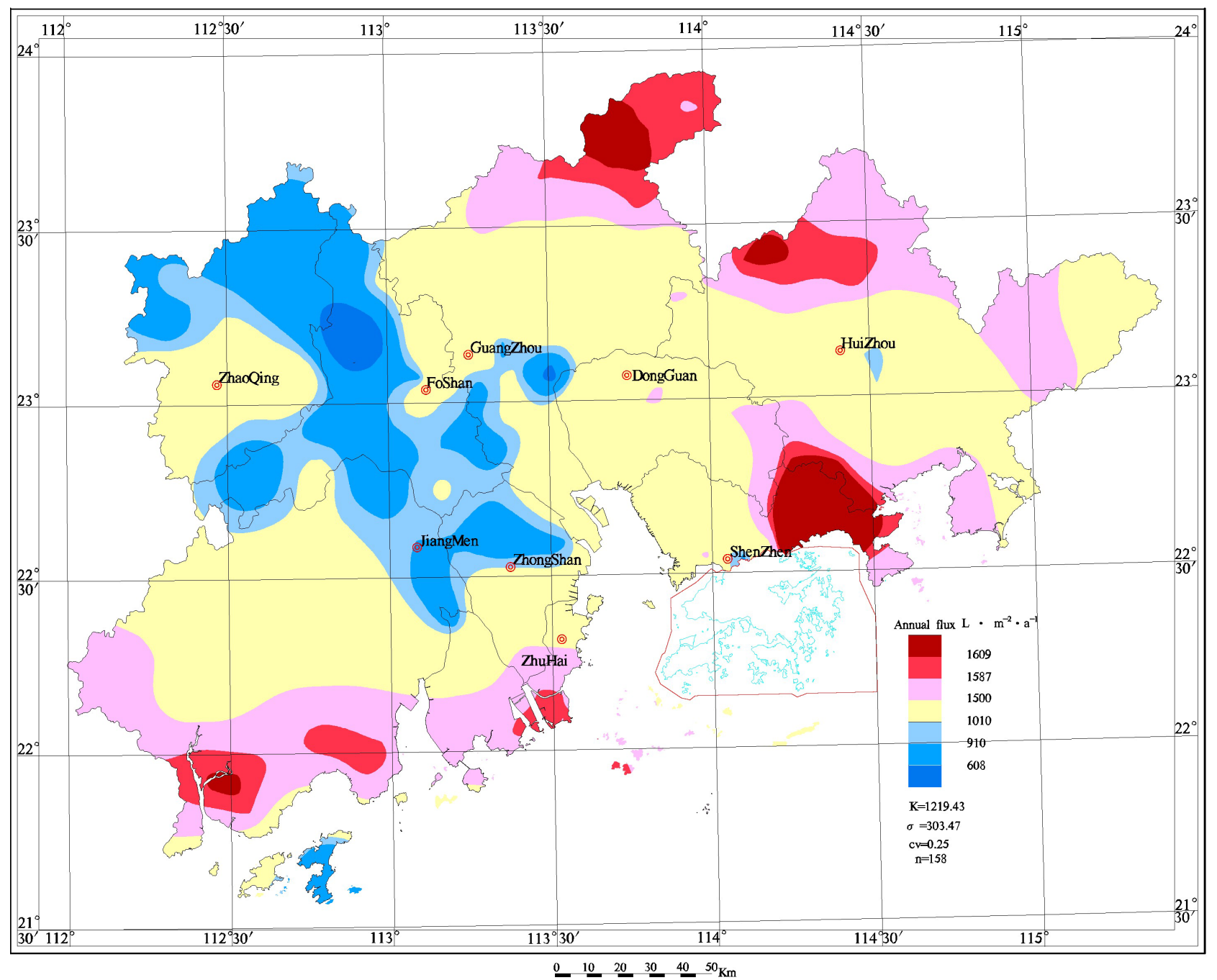

Figure 2. Distribution of annual flux of wet deposition (Atmospheric precipitation) in the Parcel River delta.

Cities, in the south part of Guangzhou City, and in the north part of Zhongshan City. Such coastal areas as Huizhou, Zhuhai, and Jiangmen Cities have of high values the rest areas are dominated by middle values. Huizhou City and the north part of Guanzhou City seem to be special cases in which the annual flexes of wet deposition are very high. What meteorological factors control them is not known at present. It is no doubt that how far from the ocean should be an important factor to determine how many wet deposition.

\section{Conclusion}

1) The average annual fluxes of these eight heavy metal elements of $\mathrm{Cr}, \mathrm{Ni}$, $\mathrm{Cu}, \mathrm{Pb}, \mathrm{As}, \mathrm{Hg}, \mathrm{Cd}$, and $\mathrm{Zn}$ have no obvious difference between dry deposition and wet deposition are not obvious in the Parcel River delta, and so these elements might be at an equilibrium or quasi-equilibrium state between dry deposition and wet deposition.

2) In the Parcel River delta economic region, the annual fluxes of dry deposi- 
tions average $81.49 \mathrm{~g} / \mathrm{m}^{2}$, while the annual fluxes of wet depositions average $1218.40 \mathrm{~L} / \mathrm{m}^{2}$.

\section{Acknowledgements}

This study was supported by Beijing Municipal Science and Technology Project (Z191100001419015).

\section{Conflicts of Interest}

The authors declare no conflicts of interest regarding the publication of this paper.

\section{References}

Al-Khashman, O. A. (2009). Chemical Characteristics of Rainwater Collected at a Western site of JORDAN. Atmospheric Research, 91, 53-61.

Budhavant, K. B., Rao, P. S. P., Safai, P. D., \& Ali, K. (2011). Influence of Local Sources on Rainwater Chemistry over Pune Region, India. Atmospheric Research, 100, 121-131.

Cheng, M. C., \& You, C. F. (2010). Sources of Major Ions and Heavy Metals in Rainwater Associated with Typhoon Events in Southwestern Taiwan. Journal of Geochemical EXploration, 105, 106-116.

Das, N., Das, R., Chaudhury, G. R., \& Das, S. N. (2010). Chemical Composition of Precipitation at Background Level. Atmospheric Research, 95, 108-113.

Gong X. Y., Qi, S. H., Lv, C. L., Wang, W., Su, Q. K., \& Fang, M. (2006). Atmospheric Deposition of Heavy Metals to Xinghua Bay, Fujian Province. Research of Environmental Sciences, 19, 31-34.

Han, Y. M., Du, P. X., Cao, J. L., et al. (2006). Multivariate Analysis of Heavy Metal Contamination in Urban Dusts of Xi'an, Central China. Science of the Total Environment, 335, 176-186.

Lu, L., Zhu, L. X., Cen, K., Zhao, L. S., Mao, J. W., Zhao, Y. Y., \& Du, H. Y. (2012). The Collection Methods and Application Examples of Atmospheric Dry and Wet Depositions. Proc. 11th Deposits National Research Forum DNRF17, Guiyang, China, 1157-1158.

Singh, A. K., \& Mondal, G. C. (2008). Chemical Characterization of Wet Precipitation Events and Deposition of Pollutants in Coal Mining Region, India. Journal of Atmos pheric Chemistry, 59, 1-23.

Zhang, L. C., Ji, Z. S., \& Zhang, S. (2006). The Geochemical Research of the Water in the Changjiang River System. China Environmental Science Press, 2006, 50-59.

Zhu, L. X., Ma, S. M., Zhou, G. H., \& Zheng, L. G. (2002). Characters of Soil Elements and Its Tract Application in Alluvial Plain. Geology and Prospecting, 38, 56-59 